\title{
Corrigendum
}

\section{Generative processes for revitalizing historic towns or heritage districts}

\author{
Besim S. Hakim
}

URBAN DESIGN International (2008) 13, 210. doi:10.1057/udi.2008.19

\section{Correction to:}

URBAN DESIGN International (2007) 12, 87-99, doi:10.1057/palgrave.udi.9000194

In the above paper, the orientation and description of the photo in Figure 3 were incorrect. The corrected version of the description and photo are as follows:

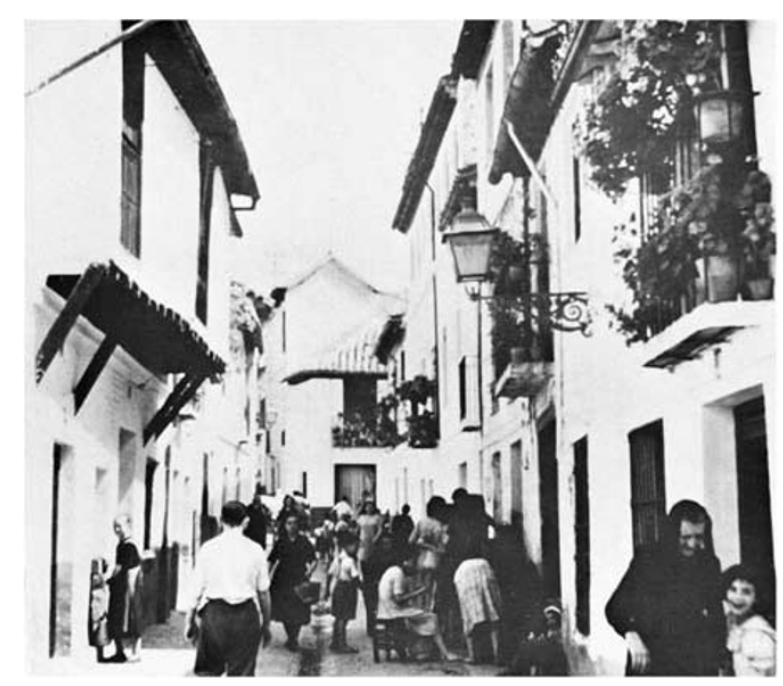

Figure 3. A street scene in the Albaicin quarter, Granada, Spain. The Fina is fully utilized in the structures by projections from the upper levels and by its use by the people without obstructing the public-right-of-way. The result is a dynamic built and social environment. Photo by Arthur Erickson from the early 1960s. 